\title{
Effects of Early Unilateral Blur on the Macaque's Visual System. III. Physiological Observations
}

\author{
J. Anthony Movshon, ${ }^{1}$ Howard M. Eggers, ${ }^{2}$ Martin S. Gizzi, ${ }^{1, a}$ Anita E. Hendrickson, ${ }^{3,4}$ Lynne Kiorpes, ${ }^{4,5,6}$ and \\ Ronald G. Boothe $e^{4,5, c}$ \\ 'Department of Psychology, New York University, New York, New York. 10003; 'Harkness Eye Institute, College of \\ Physicians and Surgeons, Columbia University, New York, New York 10036; and Departments of 3Biological Structure, \\ ${ }^{4}$ Ophthalmology, and ${ }^{5}$ Psychology, University of Washington, Seattle, Washington 98195
}

We studied the properties of visual cortical and lateral geniculate neurons in $\mathbf{5}$ macaque monkeys raised with the vision of one eye blurred by daily instillation of atropine. This rearing reduced the degree of binocular interaction in striate cortical neurons and caused a modest shift in eye dominance away from the atropine-treated eye. It also led to a difference in the spatial properties of neurons driven by the 2 eyes: neurons driven by the treated eye tended to have lower optimal spatial frequencies, poorer spatial resolution, and lower contrast sensitivity than neurons driven by the untreated eye. Some of the few binocularly driven neurons had receptive fields with sharply different spatial properties in the 2 eyes, with the treated eye's receptive field always having poorer spatial resolution. In striate cortex, the effects on neuronal spatial properties were less marked in layer 4 than in more superficial or deeper layers; there was no difference in the spatial properties of lateral geniculate neurons driven by the 2 eyes. A small sample of extrastriate cortical neurons from a single animal showed effects similar to those seen in striate cortex. The striate cortical changes varied consistently from animal to animal: The less affected animals had no discernible eye dominance shift and relatively small differences in spatial properties between the eyes; the more affected animals had substantial eye dominance shifts and larger interocular spatial differences. These variations were also reflected in, and consistent with, behavioral and anatomical measurements performed in the same monkeys.

Depriving an animal of vision in one eye early in life profoundly alters the function of its central visual pathways. Following even

\footnotetext{
Received Apr. 10, 1986; revised Sept. 25, 1986; accepted Sept. 27, 1986.

This research was supported by NIH Grants EY 1208, EY 1730, EY 2017, EY 2530, RR 166, and HD 2274. J.A.M. held a Research Career Development Award from NIH (EY 187). M.S.G. was partly supported by a grant from the New York State Health Research Council. A.E.H. is the recipient of a Dolly Green Scholar Award from Research to Prevent Blindness, Inc. We are grateful to Bente Noble, Harriet Friedman, and Toni Wolinsky for their expert histological assistance, to Earl L. Smith III for his assistance in some of the recordings, and to Michael Hawken for his comments on an earlier version of the manuscript.

Correspondence should be addressed to Dr. I. A. Movshon, Department of Psychology, New York University, 6 Washington Place, New York, NY 10003.

Present address: Department of Neurology, Mount Sinai Medical School, New York, NY 10036.

b Present address: Department of Psychology, New York University, New York, NY 10003.

c Present address: Department of Psychology, Emory University, Atlanta, GA 30322.

Copyright (C) 1987 Society for Neuroscience $0270-6474 / 87 / 051340-10 \$ 02.00 / 0$
}

a modest period of such deprivation, most neurons outside layer $4 \mathrm{C}$ of the visual cortex lose their functional connections with the deprived eye and respond only to visual stimuli delivered to the other eye (Wiesel and Hubel, 1963; Baker et al., 1974; Hubel et al., 1977; Blakemore et al., 1978; von Noorden and Crawford, 1979; LeVay et al., 1980). Visual deprivation is usually achieved by suture of the eyelids, which abolishes virtually all patterned stimulation of the retina and substantially reduces retinal illumination. It appears that it is the prevention of form vision that is critical, since the effects follow abolition of patterned stimulation even when unaccompanied by a change in retinal illumination, but do not occur when retinal illumination alone is reduced (Wiesel and Hubel, 1965; Blakemore, 1976; von Noorden and Crawford, 1977).

The effects of complete form deprivation are presumably as extreme as they are because the deprivation is total, and in recent years several groups have studied the effect of partial deprivation on visual function, using atropine penalization or blurring lenses to degrade the retinal image in one eye, rather than abolishing it completely. This reportedly causes effects like those of monocular occlusion but of less severity (Crawford, 1978; Blakemore and Eggers, 1978; Ikeda and Tremain, 1978). Deprivation by image blur predominantly affects the fine details or high spatial frequency components of the visual image. There is considerable evidence that different spatial frequencies are processed by different populations of visual cortical neurons in both cats and monkeys (Maffei and Fiorentini, 1973; Movshon et al., 1978c; De Valois et al., 1982). One may view the effects of a period of deprivation either as a generalized response by the visual cortex to reduced input from one eye or as a specific response by the particular groups of neurons whose responses are most affected by the deprivation. It is therefore natural to inquire whether the effects of blur are most strongly expressed in groups of neurons that would normally respond to stimuli of relatively high spatial frequency.

Rearing animals with a blurred retinal image also approximates the conditions that lead in humans to anisometropic amblyopia, in which the visual capabilities of the blurred eye are reduced, even when the conditions producing blur are corrected (Sen, 1980). We have found amblyopia-like effects of early unilateral blur on the spatial vision of monkeys (Boothe et al., 1982; Kiorpes et al., 1987). Anatomical studies in these same monkeys suggest that the blur primarily affects the portions of the visual thalamus and cortex responsible for the relay of information about fine spatial detail (Hendrickson et al., 1987). We report 
here the results of cortical and thalamic recordings from monkeys raised from birth with degraded vision in one eye produced by daily unilateral instillation of atropine. In these recordings we not only studied the eye dominance of cortical neurons, but also sought to establish whether there was any effect of the deprivation on the spatial characteristics of the neurons' visual receptive fields. Our results indicate that important effects of form deprivation by atropinization are expressed in changes in the spatial properties of visual cortical neurons and that changes in cortical eye dominance are less obvious in this casc. Wc have briefly presented some of these results elsewhere (Hendrickson et al., 1982).

\section{Materials and Methods}

Subjects. In these experiments we used 5 of the 8 pigtailed macaque monkeys (Macaca nemestrina) whose rearing and treatment were described in the first of these papers (Kiorpes et al., 1987). The retinal image of one eye of each animal was blurred by twice-daily instillation of atropine from shortly after birth to at least the age of 6 months. The vision of 4 of the 5 monkeys used in the physiological experiments (LD, $\mathrm{TC}, \mathrm{DH}$, and NW) was tested behaviorally. All showed reduced contrast sensitivity when tested through the atropine-treated eye. The visual performance of the fifth monkey (OL) was evaluated using evoked potential methods, which revealed a similar performance deficit in the treated eye. Details of these measurements may be found in the first of these papers (Kiorpes et al., 1987); they are summarized, along with the rearing and refractive histories of the animals and the anatomical findings (Hendrickson et al., 1987), in Table 1. Control data for cortical recordings were obtained from I Macaca nemestrina and 3 Macaca fascicularis that were reared normally. The electrophysiological experiments on the atropinized monkeys were performed blind, in that the experimenters involved in the recordings did not know which eye had been treated or the details of the behavioral effects in a particular animal until after the recordings were completed.

The monkeys were initially anesthetized with ketamine, and surgery was conducted first under halothane and then, after venous cannulation, sodium thiopental anesthesia. After surgery was complete, the animal was paralyzed with an infusion of muscle relaxant (pancuronium bromide, $0.1 \mathrm{mg} / \mathrm{kg} / \mathrm{hr}$ ), in a dextrose Ringer's solution ( $5-10 \mathrm{ml} / \mathrm{hr}$ ). Rectal temperature was maintained near $36.8^{\circ} \mathrm{C}$ with a thermostatically controlled heating pad. Anesthesia was maintained by artificial ventilation with a mixture of $\mathrm{N}_{2} \mathrm{O}, \mathrm{O}_{2}$, and $\mathrm{CO}_{2}$ (typically 58:40:2), supplemented with intravenous infusion of sodium pentobarbital $(1-4 \mathrm{mg} / \mathrm{kg} / \mathrm{hr})$. The end-expiratory $\mathrm{PCO}_{2}$ was continuously monitored and maintained near $4.0 \%$ by appropriately changing the artificial ventilation. ECG and EEG were monitored continuously to ensure the adequacy of anesthesia and the soundness of the animal's physiological condition.

In 4 monkeys (LD, TC, DH, and NW), recordings were made from regions of primary visual cortex representing the center of gaze, in long, obliquely directed microelectrode penetrations oriented so that they were roughly parallel to the lip of the lunate sulcus and therefore crossed the cortical eye dominance column system roughly at right angles (LeVay et al., 1975). We isolated the activity of single neurons with tungstenin-glass micruelectrodes (Levick, 1972; Merrill and Ainsworth, 1972), introduced through a small craniotomy and durotomy enclosed in a chamber that was filled with agar gel during recording. In order to make our recordings from locations evenly spaced along the electrode tracks, we used a modified version of the sampling protocol devised by Stryker and Sherk (1975) and accepted no neuron for study unless it was at least $80 \mu \mathrm{m}$ from a previously studied neuron.

In the fifth monkey $(\mathrm{OL})$, recordings were made from both the parvocellular and magnocellular divisions of the lateral geniculate nucleus (LGN) containing the representation of the central $10^{\circ}$ of the visual field.

The corneas were protected with zero-power contact lenses selected by keratometry, and supplementary lenses chosen by streak retinoscopy were used to make the retinae conjugate with a screen $90 \mathrm{~cm}$ distant. We regularly checked our choice of supplementary lens by changing its power in 0.5 diopter (D) steps while monitoring the responses of visual neurons and selecting the lens that permitted the highest spatial resolution. The lenses chosen in this way rarely differed by more than $1 \mathrm{D}$ from those selected by retinoscopy. We used an ophthalmoscope fitted with a removable corner-cube to project the positions of the foveas onto the tangent screen on which receptive fields were mapped.

All cortical neurons had receptive fields between $0.5^{\circ}$ and $2.5^{\circ}$ from the center of the fovea. The visual stimuli were bright or dark bars and edges or moving sinusoidal gratings generated by a PDP $11 / 34$ computer on the face of a display oscilloscope subtending $6^{\circ}$ at the animal's eyes; the mean luminance of the display was held constant at $40 \mathrm{~cd} / \mathrm{m}^{2}(\mathrm{P} 31$ phosphor). The orientation, position, spatial frequency, drift rate, and contrast of the stimuli were controlled by the experimenter by means of potentiometers and a joystick; when ohjective measurement of some receptive field property was desired, the computer presented a selected set of test stimuli in a randomly interleaved manner while collecting averaged response histograms, using methods described in detail elsewhere (Movshon et al., 1978a; Tolhurst et al., 1983). Receptive fields were classified as simple, complex, hypercomplex, or nonoriented by the criteria of Hubel and Wiesel (1968), corroborated by the form of their responses to sinusoidal gratings (Movshon et al., 1978a, b; De Valois et al., 1982). For each neuron, we established the eye dominance, using the 7-point scale of Hubel and Wiesel (1962), and the optimal orientation and direction of motion, if any. Using sinusoidal grating stimuli delivered to the neuron's dominant eye, we next determined the most effective spatial frequency, using the optimal orientation, direction, and drift rate. At this spatial frequency, we then measured the neuron's contrast sensitivity (the reciprocal of the lowest contrast at which the optimal grating elicited reliable responses: Enroth-Cugell and Robson, 1966; Movshon et al., 1978c). Finally, we determined the neuron's spatial resolution, the highest spatial frequency to which the neuron gave reliable responses when the contrast of the grating was near 1 . We occasionally made repeated measurements of these subjectively estimated parameters, using either the same or a different experimenter; such repeated estimates rarely differed from one another by more than $10 \%$. When we had occasion to examine spatial frequency tuning objectively, the resulting values for optimal spatial frequency and spatial resolution typically agreed with our subjective estimates to about the same accuracy.

We mapped the receptive fields of isolated geniculate neurons with stationary and moving white and colored targets, and classified them according to the scheme of Wiesel and Hubel (1966). We then proceeded to examine their spatial frequency tuning characteristics by measuring the responses elicited by drifting achromatic sinusoidal gratings of fixed high contrast $(0.5)$ presented in a pseudorandom sequence on the CRT. We also noted each neuron's latency to brief bipolar electrical pulses ( $50 \mu \mathrm{sec}$, typically $0.1-1 \mathrm{~mA}$ ) delivered by an isolated stimulator through a pair of sharpened epoxy-insulated tungsten electrodes stereotaxically placed in the optic chiasm.

Electrolytic lesions were made at selected points along each electrode track by passing direct current through the recording electrode $(2 \mu \mathrm{A}$, $2 \mathrm{sec}$, tip negative). After the recordings, which lasted between 18 and $72 \mathrm{hr}$, most animals were exposed to selected visual patterns while the metabolic marker $1{ }^{14} \mathrm{C}$-2-deoxy- $d$-glucose was administered (see the preceding paper, Hendrickson et al., 1987, for details of these experiments). The animals were then killed with an overdose of barbiturate and perfused with $4 \%$ paraformaldehyde in phosphate buffer. For reconstruction of the electrode tracks, frozen sections were cut at $40 \mu \mathrm{m}$ in a plane parallel to the tracks and stained with cresyl violet. All cortical penetrations save one (discussed below) were verified to lie entirely within the opercular portion of the striate cortex.

\section{Results}

We recorded from 316 visually responsive striate cortical neurons in 10 microelectrode penetrations in 6 hemispheres from monkeys $\mathrm{LD}, \mathrm{TC}, \mathrm{DH}$, and $\mathrm{NW}$. In addition, we recorded 54 responsive neurons in a single penetration accidentally directed into prestriate cortex on the prelunate gyrus of monkey TC, and 83 neurons in 5 penetrations into the LGNs of monkey OL. Of the V1 neurons, $23(8 \%)$ were unresponsive to stimuli presented on the pale green CRT face (although they could be activated by colored and sometimes by white stimuli presented on a tangent screen); for the remaining 292 (92\%), we collected some or all of the information detailed in Materials and Methods above. Of the 54 prelunate neurons, $6(11 \%)$ were unresponsive to stimuli on the CRT, and the spatial properties of the remaining 
Table 1. Summary dala: behavior and morphology

\begin{tabular}{|c|c|c|c|c|c|c|c|c|}
\hline \multirow[b]{2}{*}{ Characteristic } & \multicolumn{8}{|l|}{ Monkey } \\
\hline & LD & $\mathrm{TC}$ & $\mathrm{DH}$ & NW & GO & GZ & $\mathrm{OH}$ & $\mathrm{OL}$ \\
\hline \multicolumn{9}{|l|}{ Rearing history } \\
\hline Eye treated & $\mathbf{R}$ & $\mathrm{L}$ & $\mathbf{R}$ & $\mathrm{L}$ & $\mathrm{L}$ & $\mathbf{R}$ & $\mathbf{R}$ & $\mathbf{R}$ \\
\hline Atropine begun (d) & 14 & 10 & 5 & 10 & 6 & 13 & 14 & 2 \\
\hline Atropine ended (mo.) & 7 & 8 & 10 & 8 & 6 & 7 & 6 & 6 \\
\hline Sacrificed (mo.) & 30 & 25 & 22 & 13 & 9 & 10 & 12 & 14 \\
\hline \multicolumn{9}{|l|}{ Final refraction } \\
\hline UE & +1.50 & +3.25 & 0.00 & +2.00 & - & +1.00 & - & +1.50 \\
\hline $\mathrm{TE}$ & +2.75 & +3.25 & +6.00 & +5.00 & - & +2.50 & - & +3.50 \\
\hline \multicolumn{9}{|l|}{ Behavioral and EP data } \\
\hline \multicolumn{9}{|l|}{ Final acuity } \\
\hline UE & 34.9 & 31.5 & 36.9 & 29.6 & $57.5^{a, b}$ & 43.0 & $19.3^{a}$ & $22.8^{b}$ \\
\hline TE & 29.3 & 28.1 & 3.7 & 6.7 & $18.7^{b}$ & 4.2 & $13.3^{a}$ & $5.3^{b}$ \\
\hline \multicolumn{9}{|l|}{ Log difference } \\
\hline Contrast Sensitivity & 0.58 & 0.23 & 0.77 & 0.85 & 0.03 & 1.39 & 0.10 & 0.20 \\
\hline Peak SF & 0.29 & 0.08 & 0.74 & 0.64 & 0.30 & 0.89 & 0.04 & 0.30 \\
\hline Cutoff SF & 0.08 & 0.05 & 1.00 & 0.65 & 0.49 & 1.01 & 0.16 & 0.63 \\
\hline \multicolumn{9}{|l|}{ Morphology } \\
\hline \multicolumn{9}{|l|}{ LGN cell size } \\
\hline Parvocellular & $\mathrm{UE}>\mathrm{TE}$ & $\mathrm{UE}>\mathrm{TE}^{c}$ & $\mathrm{UE}>\mathrm{TE}$ & $\mathrm{UE}>\mathrm{TE}$ & $\mathrm{UE}>\mathrm{TE}^{d}$ & $\mathrm{UE}>\mathrm{TE}$ & $\mathrm{UE}>\mathrm{TE}^{d}$ & $\mathrm{UE}>\mathrm{TE}$ \\
\hline Magnocellular & $\mathrm{UE}<\mathrm{TE}$ & $\mathrm{UE}=\mathrm{TE}$ & $\mathrm{UE}=\mathrm{TE}$ & $\mathrm{UE}>\mathrm{TE}$ & $\mathrm{UE}>\mathrm{TE}^{d}$ & $\mathrm{UE}=\mathrm{TE}$ & $\mathrm{UE}=\mathrm{TE}^{d}$ & $\mathrm{UE}>\mathrm{TE}$ \\
\hline \multicolumn{9}{|l|}{ Cortical CO } \\
\hline \multicolumn{9}{|l|}{ Cortical $2 \mathrm{dG}$} \\
\hline Stimuluse & High SF & Mid SF & - & Mid SF & Mid SF & Complex & Complex & - \\
\hline Retinal locus & $\mathrm{R}, \mathrm{L}$ nasal & $\mathrm{R}, \mathrm{L}$ nasal & - & $\mathrm{R}, \mathrm{L}$ nasal & $\mathrm{R}, \mathrm{L}$ nasal & L eye & $R$ eye & - \\
\hline UE ODC pattern & Wide & Wide & - & Indistinct & Wide & Wide & - & - \\
\hline UE activity & High & High & - & Low & High & High & - & - \\
\hline TE ODC pattern & Indistinct & Indistinct & - & Indistinct & Narrow & - & Narrow & - \\
\hline TE activity & Low & Low & - & Low & High & - & High & - \\
\hline
\end{tabular}

$\overline{\mathrm{UE}}$, untreated eye; $\mathrm{TE}$, treated eye; $\mathrm{ODC}$, ocular dominance column; $\mathrm{CO}$, cytochrome oxidase; $\mathrm{EP}$, evoked potential.

${ }^{a}$ High-frequency portion poorly defined.

${ }^{b}$ Evoked potential measurements.

c Effect only in LGN ipsilateral to atropinized eye.

${ }^{d}$ Measured only ipsilateral LGN.

' High, 6-9 c/deg.; mid, 4.5-6 c/deg; complex, stimulation board.

$48(89 \%)$ were characterized. Of the 83 LGN neurons, $76(92 \%)$ were fully characterized.

\section{Striate cortex}

The visual cortex seemed qualitatively normal in all animals. Most neurons gave vigorous responses to moving bars, edges, and gratings, and we encountered no cortical regions in which visual responsiveness was markedly reduced or absent. Figure 1 summarizes the data obtained in one electrode penetration from monkey LD. The right side of the figure shows a tracing of the histological section (which passed obliquely through the cortex) containing the electrode track; the positions of the track and of the 2 marking lesions are indicated. In the middle and on the left, the properties of 32 isolated cortical neurons are summarized as a function of their position. The left side plots the spatial frequency tuning properties of 31 of these neurons (the remaining neuron, isolated in the lower part of layer 3, was unresponsive to the CRT display). For each neuron, the optimal spatial frequency is plotted as a filled symbol and the spatial resolution is plotted as an open symbol. The middle panel plots the eye dominance of each neuron. In this case, the atropinized eye (A) was contralateral and the untreated eye (U) was ipsilateral to the recording site.

There are several interesting features to the data from this penetration. First, there was a marked absence of neurons in eye dominance groups 3-5 (that is, neurons with strong functional inputs from both eyes): only 4 of the 32 neurons were strongly binocular. Second, neurons driven predominantly by one eye or the other were clustered in groups, the eye dominance columns of Hubel and Wiesel $(1968,1977)$. In monkeys monocularly deprived by lid suture, one would expect to find few binocular neurons, as we found here. More obviously, though, one would expect few if any neurons, except possibly in layer $4 \mathrm{C}$, to be driven strongly from the deprived eye (Baker et al., 1974; Hubel et al., 1977; Blakemore et al., 1978; LeVay et al., 1980). In this penetration, neurons strongly dominated by the 


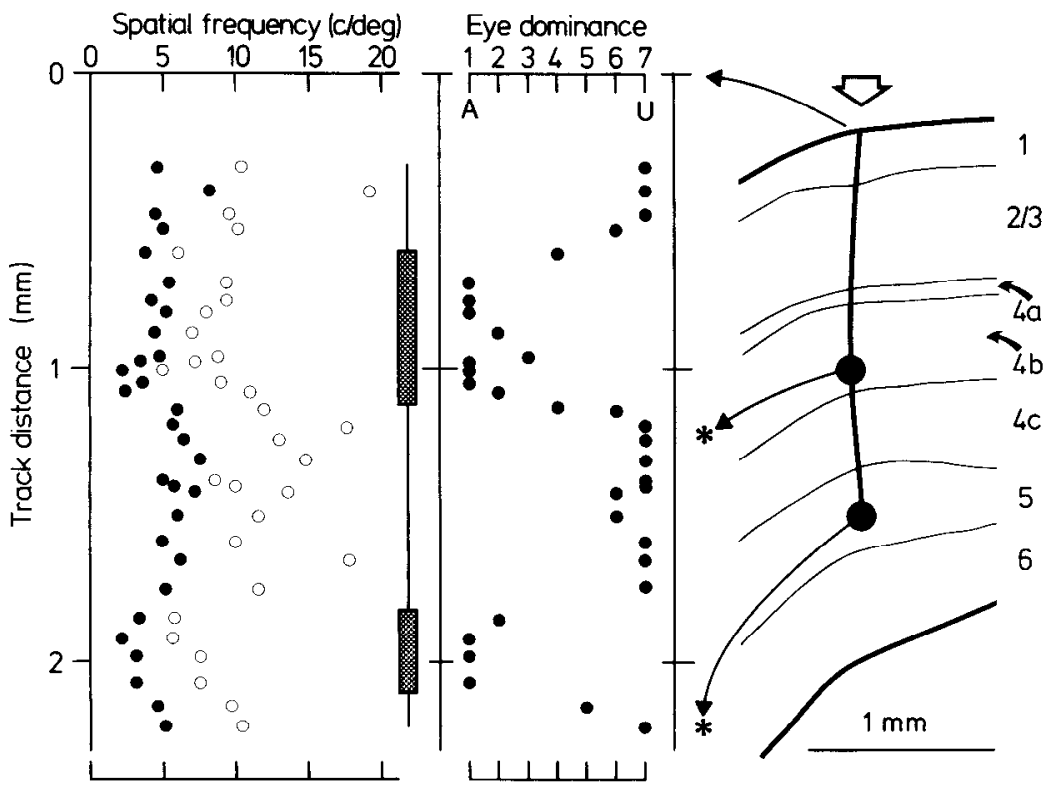

Figure 1. Summary of a single micruelectrode penetration into the left striate cortex of monkey LD. Right, Tracing of the reconstructed electrode track (open arrow), including the locations of 2 electrolytic lesions (filled circles). Left and center, Properties of 32 neurons encountered on this electrode track as a function of their location in the track; the arrows and asterisks mark the locations of landmarks in the track. The central panel shows the eye dominance of the neurons - the atropinetreated eye $(A)$ was contralateral to the recording site. The vertical bar to the left of this panel marks the overall eye dominance of regions of the penetration, with the thickened bars marking regions dominated by the treated eye. The left-hand panel shows the optimal spatial frequency (filled circles) and spatial resolution (open circles) of the neurons.

treated and untreated eyes were roughly equal in number; moreover, most of the neurons driven by the treated eye happened to be outside layer 4. Inspection of the spatial frequency data on the left, however, reveals that the reduced binocularity was not the most remarkable feature of the data from this penetration. Neurons in regions dominated by the atropinized eye (marked by bars in the center of the figure) tended to have a lower optimal spatial frequency and poorer spatial resolution than neurons driven by the normal eye. This is most clearly seen at depths near 1.1 and $1.9 \mathrm{~mm}$, where transitions in eye dominance were clearly accompanied by changes in the spatial properties of neurons. It is, of course, possible that effects of this sort in any given penetration might be related to transitions between cortical layers or between aggregates of neurons preferring similar spatial frequencies (Maffei and Fiorentini, 1977; Tootell et al., 1981; Tolhurst and Thompson, 1982), which serendipitously coincide with changes in eye dominance. Later in the paper we present evidence that this was not the case.
Eye dominance. Figure 2 summarizes our data on the eye dominance of neurons recorded from V1. The eye dominance of 384 neurons recorded from the striate cortex of 4 normal monkeys is shown for comparison in Figure $2 A$; this distribution is similar to that reported by others in the normal macaque's cortex (e.g., Hubel and Wiesel, 1968; Schiller et al., 1976; Blakemore et al., 1978). For the remaining data in this figure, and in all subsequent figures, the eye dominance scale is arranged so that cells driven only by the treated eye (whether contra- or ipsilateral to the recording site) fall in group 1 and those driven by the untreated eye fall in group 7 . Figure $2 B$ shows the eye dominance of all 316 neurons recorded from V1 of the atropinetreated monkeys. It is obvious that there was a very considerable reduction in the proportion of binocularly driven neurons in the atropinized animals: Only 70 of the 316 neurons from these animals (22\%) fell in eye dominance groups $3-5 ; 178$ of the 384 neurons from normal animals $(45 \%)$ were in these strongly binocular groups. Interestingly, despite the reduction in binocular-
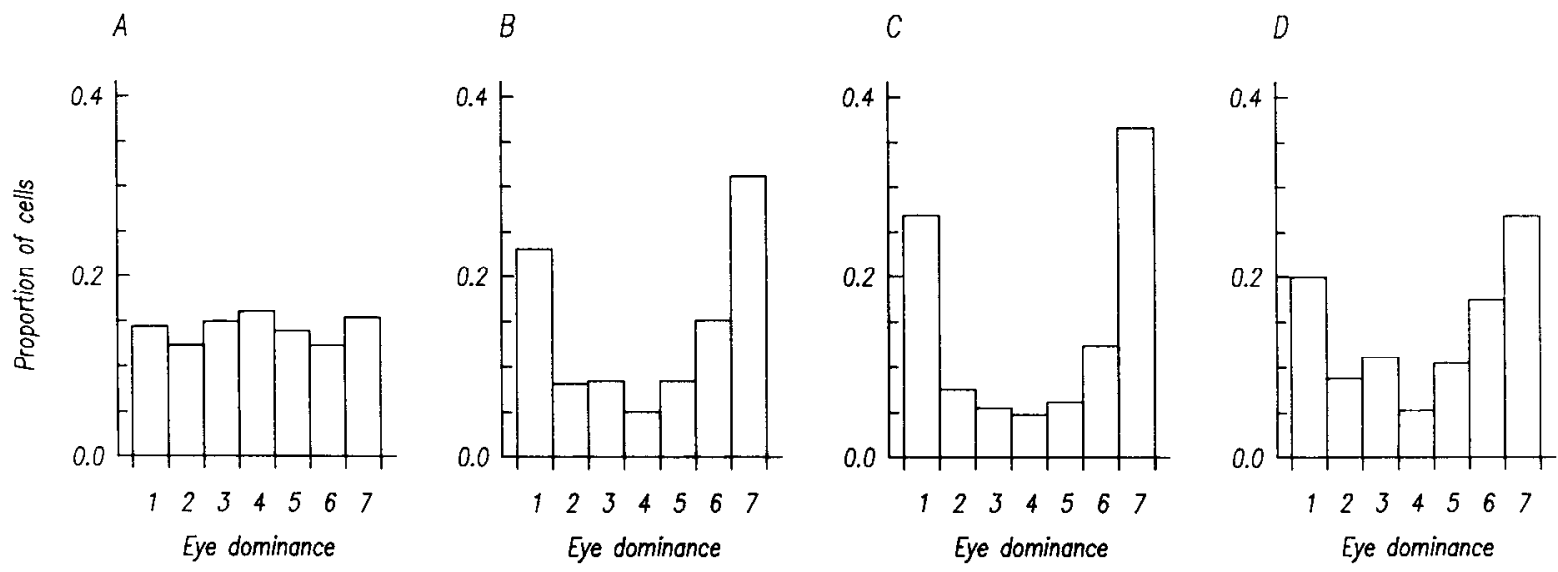

Figure 2. Eye dominance distributions for neurons recorded from the striate cortex of 4 normally reared monkeys $(A)$ and for neurons recorded from the striate cortex of atropine-treated monkeys $\mathrm{LD}, \mathrm{TC}, \mathrm{DH}$, and NW $(B-D)$. In parts $B-D$, and hereafter, the eye dominance scale is transformed so that the atropine-treated eye is always treated as contralateral: Cells dominated by this eye fall in groups $1-3$, while cells dominated by the untreated eye fall in groups 5-7. A, Eye dominance of 384 cells from normally reared monkeys. $B$, Eye dominance of all 316 neurons from the atropine-treated monkeys. $C$, Eye dominance of 145 neurons recorded in the cortex contralateral to the treated eye. $D$, Eye dominance of 171 neurons recorded in the cortex ipsilateral to the treated eye. 

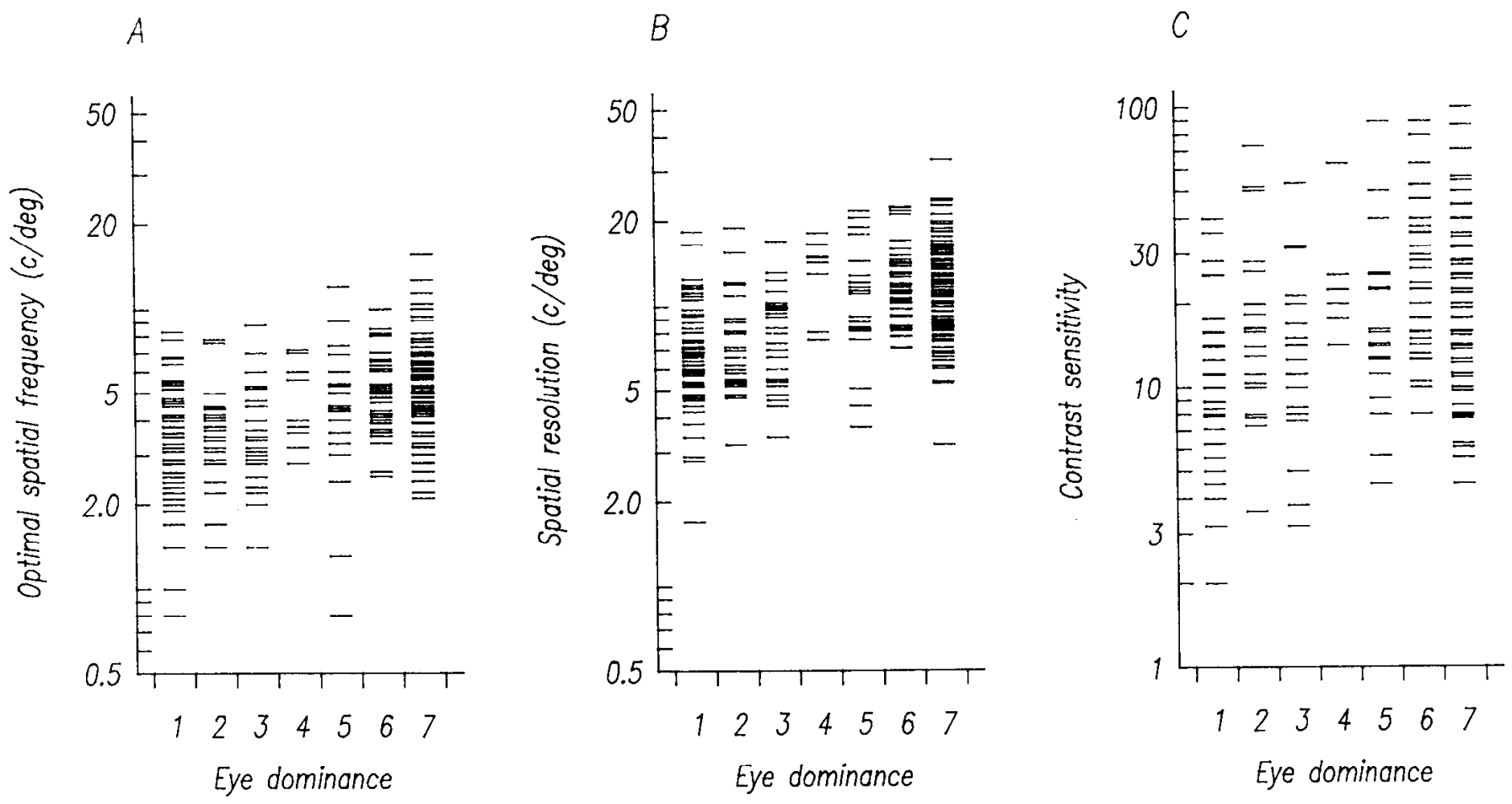

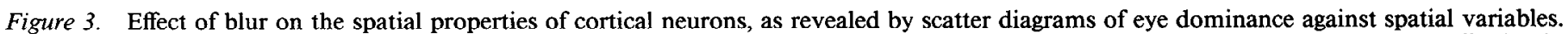

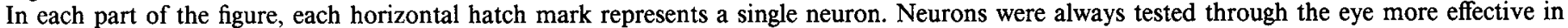

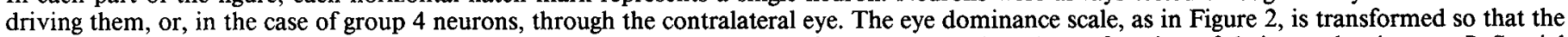

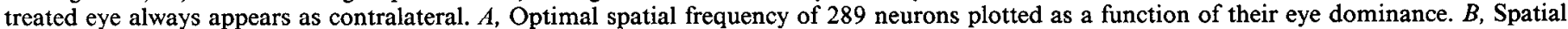

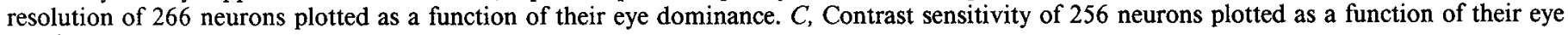
dominance.

ity evident in the distribution from the atropine animals, there was a rather modest shift in eye dominance away from the atropinized eye: 217 of the 316 neurons $(69 \%)$ could be activated from that eye, and 126 of the $316(40 \%)$ were dominated by that eye. In contrast, only 54 of the 316 neurons (17\%) recorded by LeVay et al. (1980) in 4 monocularly deprived monkeys could be activated through the deprived eye, and only 28 of the 316 $(9 \%)$ were dominated by it. Figure $2, C$ and $D$, shows separately the eye dominance distributions for neurons recorded contralateral and ipsilateral to the treated eye. There was no particular tendency for neurons recorded either contralateral or ipsilateral to the treated eye to be more or less frequently dominated by it. Binocular cells were slightly more common in the hemisphere ipsilateral to the treated eye, where 46 of the 171 neurons (27\%) fell in eye dominance groups $3-5$, than in the contralateral hemisphere, where only 24 of the 145 neurons (17\%) were in these groups.

Eye dominance and spatial properties. The data shown in Figure 1 suggest that there might be a relationship between the eye dominance of cortical neurons and their spatial characteristics in atropinized animals. Figure 3 examines this point by plotting the optimal spatial frequency (Fig. $3 A$ ), spatial resolution (Fig. $3 B$ ), and contrast sensitivity (Fig. $3 C$ ) of these neurons against their eye dominance. In each part of the figure, the abscissa is the transformed eye dominance scale used in Figure $2 A$, with the treated eye always plotted as if it were contralateral. Each hatch mark represents a single neuron. Each part of this figure reveals that neurons having different spatial properties were not uniformly distributed in eye dominance; rather, cells dominated by the treated eye were typically inferior in spatial resolution and contrast sensitivity and had lower optimal spatial frequencies than cells dominated by the untreated eye. These data can be viewed as showing a spatial frequency- and contrast-dependent effect on the eye dominance of cortical neurons. Notice, for example (Fig. $3 A$ ), that cells with optimal spatial frequencies below about $6 \mathrm{c} / \mathrm{deg}$ were about equally commonly dominated by either eye; cells with higher optimal frequencies were much more frequently dominated by the untreated eye.

The data shown in Figure 3 are presented in a different way in Figure 4, which separately shows distributions of optimal spatial frequency (Fig. 4A), spatial resolution (Fig. 4B), and contrast sensitivity (Fig. $4 C$ ) for neurons dominated by the treated (upper histograms: te) and untreated (lower histograms: ue) eyes. The dot above each histogram indicates the logarithmic mean of the distribution. For each parameter, it is clear that neurons driven by the untreated eye tended to have higher values. The mean optimal spatial frequency of neurons driven by the untreated eye was $4.81 \mathrm{c} / \mathrm{deg}, 43 \%$ higher than the mean of $3.36 \mathrm{c} / \mathrm{deg}$ shown by neurons driven by the treated eye. Similarly, the untreated eye's mean spatial resolution was 11.44 $\mathrm{c} / \mathrm{deg}, 60 \%$ higher than the treated eye's mean of $7.16 \mathrm{c} / \mathrm{deg}$; and the untreated eye's mean contrast sensitivity of 19.7 was $52 \%$ higher than the treated eye's mean of 13.0 .

Binocularly driven neurons in these animals were rather rare (Fig. 2,B-D), but for a few such neurons we measured the complete spatial frequency tuning characteristics for both eyes' receptive fields. Four examples of data of this kind are shown in Figure 5. In each case, we measured spatial frequency tuning using drifting gratings of high contrast $(0.5)$; the orientation, 

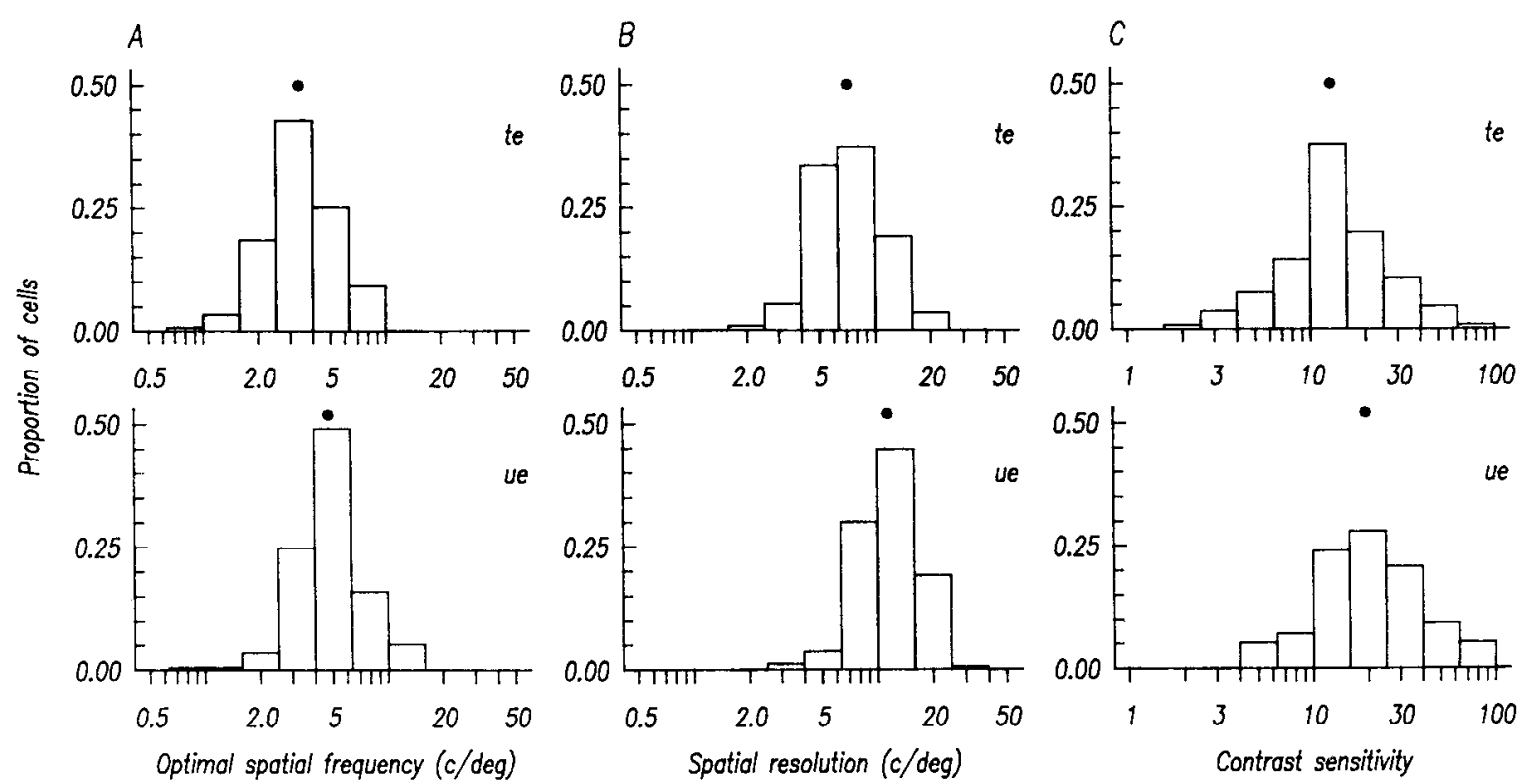

Figure 4. Distribution of spatial variables for neurons driven by the treated and untreated eyes. In each part of the figure, the upper distribution $(t e)$ is for neurons driven by the treated eye; the lower distribution (ue), neurons driven by the untreated eye. The dot above each histogram marks the logarithmic mean. $A$, Distributions of optimal spatial frequency for 119 neurons driven by the treated eye and for 170 neurons driven by the untreated eye. The logarithmic means differ by $43 \%$. B. Distributions of spatial resolution for 110 neurons driven by the treated eye and for 156 neurons driven by the untreated eye. The logarithmic means differ by $60 \%$. $C$, Distributions of contrast sensitivity for 106 neurons driven by the treated eye and for 150 neurons driven by the untreated eye. The logarithmic means differ by $52 \%$.

direction, and drift rate were optimized for each eye. Data obtained from the untreated eye are shown by open symbols, while those from the treated eye are shown by filled symbols. Note that in each case, the neuron's spatial frequency tuning extended to higher spatial frequencies in the untreated eye than it did in the treated eye. The magnitude of this interocular difference appeared to vary with the cell's optimal spatial frequency: For cells preferring relatively low spatial frequencies (Fig. 5, $A, B$ ), the effect was relatively modest; for cells preferring higher spatial frequencies (Fig. 5,C,D), the effect was larger. Thus, the 2 receptive fields of these binocularly driven neurons mirror the effects seen throughout the cortex in populations of neurons tested through one or the other of the 2 eyes (Figs. 3,4). Although data on the coincidence of spatial frequency tuning characteristics measured for the 2 receptive fields of binocular cortical neurons are not available in the literature, unpublished observations from our laboratory suggest that it is rare for the spatial frequency preferences and resolution limits to differ by more than $15 \%$ for binocular cells; we have certainly never seen differences of the magnitude shown in Figure $5, B-D$, in normally reared animals.

These data call into question the whole notion of "eye dominance" for neurons of this kind. Consider, for example, the data in Figure $5 C$. At spatial frequencies below $2 \mathrm{c} / \mathrm{deg}$, responses could be elicited only through the treated eye; at spatial frequencies above $8 \mathrm{c} / \mathrm{deg}$, responses could only be elicited through the untreated eye. Thus, depending on the test spatial frequency, this neuron could be classed in any eye dominance group between 1 and 7 . As it happens, we classified the neuron (recorded in the cortex contralateral to the atropinized cyc) as being in eye dominance group 5 , suggesting that our eye dominance test using moving light and dark bars tended to average over the differences in spatial properties between the receptive fields in the 2 eyes.
Interanimal variability. The behavioral and anatomical effects of unilateral blur vary considerably from animal to animal, and we were interested to see whether there would be any correlated variation in the cortical effects. The magnitude of the behavioral and anatomical effects of blur in the monkeys used for cortical recordings varied from rather modest (TC) to very severe (NW)

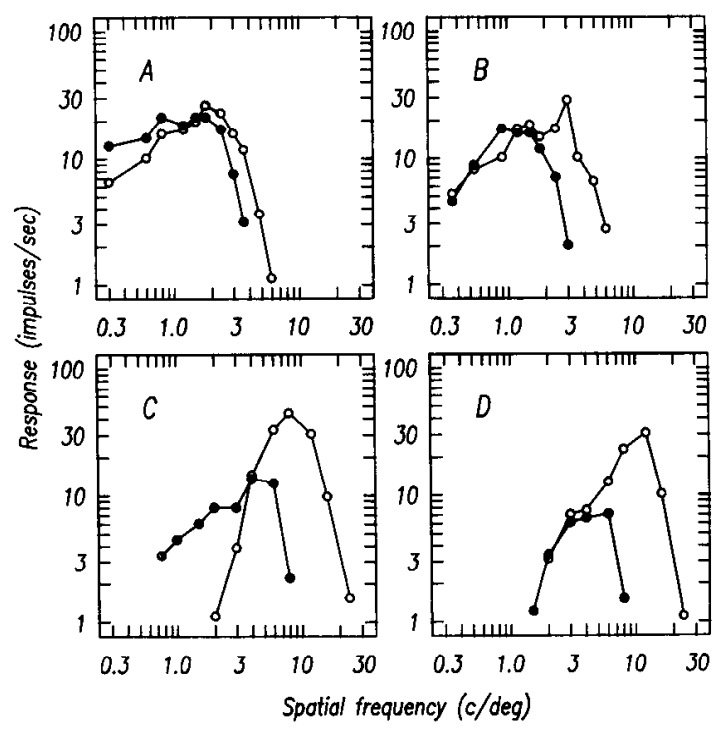

Figure 5. Spatial frequency tuning characteristics for 4 binocular neurons tested separately through each eye. Data for the treated eye are shown as filled symbols, for the untreated eye as open symbols. For all neurons, the response plotted is the mean firing rate during the presentation of the test grating less the spontaneous firing rate. $A$, Complex cell recorded from monkey TC. $B$, Simplc ccll recorded from monkcy LD. $C$, Complex cell recorded from monkey TC. $D$, Complex cell recorded from monkey LD. 

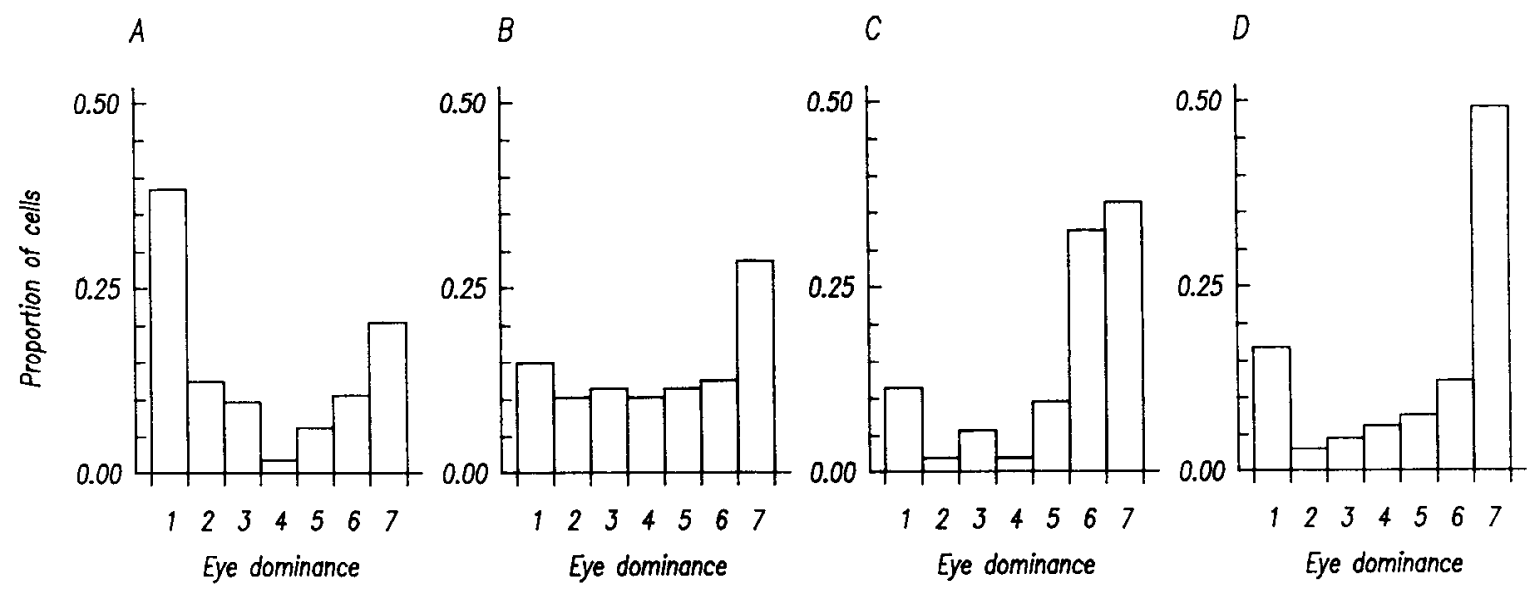

Figure 6. Eye dominance distributions for striate cortical neurons from 4 atropine-treated monkcys. As in previous figures, the data are represented as if the treated eye were contralateral, $A$, Results for 112 neurons recorded from both hemispheres of monkey TC. $B$, Results for 87 neurons recorded from both hemispheres of monkey LD. $C$, Results for 52 neurons recorded from the hemisphere ipsilateral to the treated eye of monkey DH. $D$, Results for 65 neurons recorded from the hemisphere contralateral to the treated eye of monkey NW.

(see Kiorpes et al., 1987; Hendrickson et al., 1987). Our results reveal that the magnitude of the physiological effects also varied among these animals.

Figure 6 shows separate eye dominance histograms for these 4 animals, using the modified eye dominance scale introduced in Figure 2. The histograms for monkeys TC and LD (Fig. 6, $A, B$ ) show rclatively littlc difference in the number of cells dominated by the 2 eyes; for monkey TC, in fact, the treated eye dominated more neurons than the untreated eye. Monkeys DH and NW (Fig. 6,C,D) both showed skewed distributions of cortical eye dominance, with the treated eye controlling substantially fewer neurons than the untreated eye.

Table 2 shows for each animal, in the same order as in Figure 6 , the mean and SD of the values of optimal spatial frequency, spatial resolution, and contrast sensitivity for neurons dominated by the treated and untreated eyes. There was some variation in the absolute values of optimal frequency and spatial resolution for the different animals, which is probably related to slight differences in the eccentricities of recorded neurons. But notice that the difference between the values for the treated and untreated eyes increases steadily from the top to the bottom of the table. For example, the optimal spatial frequencies of neurons dominated by TC's untreated eye were on average only $23 \%$ greater than those of neurons dominated by the treated eve; for NW, the difference was $67 \%$. The other parameters reveal a similar pattern of interanimal differences, with TC and LD showing milder effects and $\mathrm{DH}$ and $\mathrm{NW}$ showing larger ones. Taken together, the results shown in Figure 6 and Table 2 suggest that in such relatively mild amblyopes as TC and LD, the most prominent effect is that the spatial performance of neurons driven by the treated eye is impaired. More severe amblyopes such as DH and NW show this effect to a larger degree; moreover, the amblyopic eye also loses control of substantial numbers of cortical neurons, leading to a marked shift in cortical eye dominance.

Hemispheric differences. The effects of atropine treatment on geniculate cell size are more marked in the hemisphere ipsilateral to the treated eye (Hendrickson et al., 1987). Although this difference was not reflected in the overall eye dominance of cortical neurons in the treated animals (Fig. 2,C,D), it is of interest to examine hemispheric differences in the effects of the rearing on the spatial properties of cortical neurons. Table 3 presents, in a format similar to that used in Table 2, the mean and variability of the values of optimal spatial frequency, spatial resolution, and contrast sensitivity for neurons recorded in the 2 hemispheres. The table reveals that the cortex ipsilateral to the trcated cyc appeared to be morc severely affected in both contrast sensitivity and spatial resolution. The difference in mean spatial resolution in contralateral recordings was $46 \%$; in ipsilateral recordings, $70 \%$. And the difference in mean contrast sensitivity in contralateral recordings was only $22 \%$; in ipsilateral recordings, $87 \%$. The effects of blur on the optimal spatial frequencies of neurons recorded contra- and ipsilateral to the treated eye were, however, almost identical: The difference in mean optimal spatial frequency in contralateral recordings was $42 \%$; in ipsilateral recordings, $43 \%$. Thus, the overall effects of treatment on the spatial properties of cortical neurons appeared to be more severe in the cortex ipsilateral to the treated eye; this is consistent with the larger changes in geniculate cell size seen ipsilaterally in these same animals (Hendrickson et al., 1987).

Laminar variation. It is of interest to know whether the linked changes in eye dominance and spatial properties shown in Figures 3 and 4 are due to modifications of subcortical or intracortical function. The first method we used to examine this question was to compare the properties of cells recorded in different layers of the cortex. It is clear that the cortical effects of monocular deprivation in monkeys are expressed most strongly outside the portions of layer 4 receiving direct LGN input (Hubel et al., 1977; LeVay et al., 1980), and we were interested to see if there was a comparable laminar difference in the effects of blur. Table 4 shows, in a format similar to that used in Tables 2 and 3 , the values for optimal spatial frequency, spatial resolution, and contrast sensitivity for striate cortical neurons recorded in the supragranular (2,3), granular (4), and infragranular $(5,6)$ layers of the cortex. The results reveal that the effects of atropine treatment were most marked in the supra- and infragranular layers and were rather more subtle in layer 4 . For example, the difference in mean optimal frequency was only $22 \%$ for neurons recorded in layer 4 ; it was $52 \%$ for neurons in 


\begin{tabular}{|c|c|c|c|c|c|c|c|c|c|}
\hline \multirow[b]{2}{*}{ Animal } & \multicolumn{3}{|c|}{ Optimal frequency } & \multicolumn{3}{|c|}{ Spatial resolution } & \multicolumn{3}{|c|}{ Contrast sensitivity } \\
\hline & $N$ & Mean & SD & $N$ & Mean & SD & $N$ & Mean & SD \\
\hline \multicolumn{10}{|l|}{ TC } \\
\hline Untreated eye & 40 & 3.97 & 0.18 & 38 & 9.84 & 0.18 & 38 & 18.82 & 0.29 \\
\hline Treated eye & 61 & 3.22 & 0.18 & 55 & 7.15 & 0.18 & 53 & 12.66 & 0.30 \\
\hline Difference $(\%)$ & & 23.3 & & & 37.6 & & & 48.6 & \\
\hline Difference (log units) & & 0.09 & & & 0.14 & & & 0.17 & \\
\hline \multicolumn{10}{|l|}{ LD } \\
\hline Untreated eye & 43 & 5.64 & 0.20 & 40 & 12.89 & 0.18 & 38 & 20.06 & 0.32 \\
\hline Treated eye & 31 & 4.04 & 0.18 & 29 & 7.88 & 0.17 & 27 & 12.89 & 0.24 \\
\hline Difference $(\%)$ & & 39.7 & & & 63.5 & & & 55.6 & \\
\hline Difference (log units) & & 0.15 & & & 0.21 & & & 0.19 & \\
\hline \multicolumn{10}{|l|}{ DH } \\
\hline Untreated eye & 42 & 5.29 & 0.15 & 37 & 12.95 & 0.15 & 35 & 19.29 & 0.27 \\
\hline Treated eye & 10 & 3.63 & 0.20 & 9 & 7.20 & 0.22 & 9 & 11.10 & 0.23 \\
\hline Difference $(\%)$ & & 45.7 & & & 79.8 & & & 73.8 & \\
\hline Difference (log units) & & 0.16 & & & 0.25 & & & 0.24 & \\
\hline \multicolumn{10}{|l|}{ NW } \\
\hline Untreated eye & 44 & 4.46 & 0.11 & 41 & 10.47 & 0.11 & 39 & 20.67 & 0.23 \\
\hline Treated eye & 17 & 2.67 & 0.18 & 17 & 6.09 & 0.20 & 17 & 15.43 & 0.24 \\
\hline Difference (\%) & & 66.9 & & & 71.9 & & & 34.0 & \\
\hline Difference (log units) & & 0.22 & & & 0.24 & & & 0.13 & \\
\hline
\end{tabular}

The logarithmic mean value and its SD (in log units) are shown for each parameter for neurons tested through the treated and untreated eye; the interocular difference is expressed as a percentage (by which the untreated eye's value exceeds the treated eye's) and in log units.

layers 2 and 3 and $56 \%$ for neurons in layers 5 and 6 . The effects of treatment on the spatial resolution of neurons were also least marked in layer 4 , although there was a substantial change in the contrast sensitivity of neurons recorded in this layer. In contrast to the situation in monocularly deprived monkeys (LeVay et al., 1980), there was no marked difference in the eye dominance of the groups of neurons recorded in different layers, although binocularly driven neurons were somewhat more common in the superficial layers than elsewhere.

\section{Lateral geniculate nucleus}

Our second approach to the question of the origins of the spatial deficits associated with cortical inputs from the treated eye was to record from both LGNs of a single monkey (OL). This monkey showed a substantial difference in spatial resolution between the eyes as revealed by evoked potential testing (Table 1). All of the neurons we encountered seemed entirely normal in their

\begin{tabular}{|c|c|c|c|c|c|c|c|c|c|}
\hline \multirow[b]{2}{*}{ Hemisphere } & \multicolumn{3}{|c|}{$\begin{array}{l}\text { Optimal } \\
\text { frequency }\end{array}$} & \multicolumn{3}{|c|}{$\begin{array}{l}\text { Spatial } \\
\text { resolution }\end{array}$} & \multicolumn{3}{|c|}{$\begin{array}{l}\text { Contrast } \\
\text { sensitivity } \\
\end{array}$} \\
\hline & $N$ & Mean & SD & $N$ & Mean & SD & $N$ & Mean & $\mathrm{SD}$ \\
\hline \multicolumn{10}{|l|}{ Contralateral } \\
\hline Untreated eye & 72 & 4.50 & 0.12 & 67 & 10.31 & 0.14 & 63 & 18.50 & 0.25 \\
\hline Treated eye & 57 & 3.17 & 0.18 & 55 & 7.04 & 0.17 & 54 & 15.21 & 0.26 \\
\hline Difference (\%) & & 41.7 & & & 46.5 & & & 21.7 & \\
\hline Difference (log units) & & 0.15 & & & 0.17 & & & 0.09 & \\
\hline \multicolumn{10}{|l|}{ Ipsilateral } \\
\hline Untreated eye & 97 & 5.05 & 0.21 & 89 & 12.37 & 0.18 & 87 & 20.64 & 0.30 \\
\hline Treated eye & 62 & 3.54 & 0.20 & 55 & 7.29 & 0.19 & 52 & 11.02 & 0.27 \\
\hline Difference (\%) & & 42.7 & & & 69.8 & & & 87.3 & \\
\hline Difference (log units) & & 0.15 & & & 0.23 & & & 0.27 & \\
\hline
\end{tabular}

The logarithmic mean value and its SD (in log units) are shown for each parameter for neurons tested through the treated and untreated eye; the interocular difference is expressed as a percentage (by which the untreated eye's value exceeds the treated eye's) and in $\log$ units. 


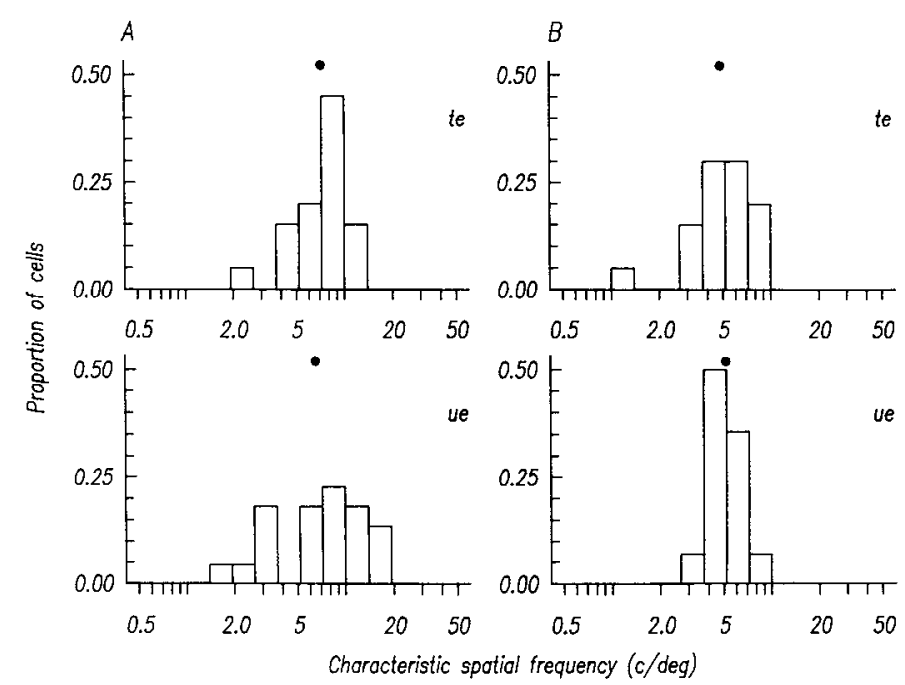

Figure 7. Distributions of characteristic spatial frequency (see text) for 76 neurons recorded from the LGNs of monkey OL. In each part of the figure, the upper distribution ( $t e)$ is for neurons driven by the treated eye; the lower distribution (ue), neurons driven by the untreated eye. The dot above each histogram marks the logarithmic mean. $A$, Distributions for 42 neurons recorded from the parvocellular layers, 20 driven by the treated eye and 22 by the untreated eye. The logarithmic means differ by $8 \%$. B. Distributions for 34 neurons recorded from the magnocellular layers, 20 driven by the treated eye and 14 driven by the untreated eye. The logarithmic means differ by $7 \%$.

receptive field properties and were driven with normal reliability and at normal latency by electrical stimulation of the optic chiasm. For 76 neurons, we measured responses to high-contrast gratings of a variety of spatial frequencies, and fit these data with the difference of 2 Gaussian functions. We used these fits to estimate the characteristic spatial frequency of the center mechanism of the geniculate receptive field, the spatial frequency at which the center mechanism's responsiveness has fallen to $1 / e$ of its maximum; this value is inversely related to the diameter of the center mechanism of the receptive field (Enroth-Cugell and Robson, 1966; Linsenmeier et al., 1982; Derrington and Lennie, 1984).

The results of this analysis are summarized in Figure 7, which shows distributions of characteristic spatial frequency for parvocellular (Fig. 7A) and magnocellular (Fig. 7B) neurons driven by the treated (upper histograms) and untreated (lower histograms) eyes. The values of characteristic frequency tended to be higher for parvocellular neurons than for magnocellular neurons, as is the case in normally reared monkeys (Kaplan and Shapley, 1982; Derrington and Lennie, 1984). There did not, however, appear to be any difference in the values for neurons driven through the 2 eyes. The mean charactcristic frequency for parvocellular neurons driven by the untreated eye $(6.5 \mathrm{c} / \mathrm{deg}$, $n=22$ ) was $8 \%$ lower than the mean for those driven through the treated eye $(7.1 \mathrm{c} / \mathrm{deg}, n=20)$; for magnocellular neurons, the mean for the untreated eye $(5.2 \mathrm{c} / \mathrm{deg}, n=14)$ was $7 \%$ higher than that for the treated eye $(4.8 \mathrm{c} / \mathrm{deg}, n=20)$. There were also no significant differences between neurons driven by the 2 eyes with respect to their responsiveness. We conclude that atropine treatment does not affect the properties of neurons in the retina or LGN, suggesting that the effects observed in the striate cortex are of intracortical rather than subcortical origin.

\section{Extrastriate cortex}

We recorded 54 neurons in a single penetration through the extrastriate cortex in monkey TC. The recordings were made from the ventral portion of the exposed lateral surface of the prelunate gyrus, and they were therefore probably located in the

Table 4. Tabulation of the values of the 3 principal spatial parameters measured for striate cortical neurons for neurons recorded in different cortical layers

\begin{tabular}{|c|c|c|c|c|c|c|c|c|c|}
\hline \multirow[b]{2}{*}{ Cortical layer } & \multicolumn{3}{|c|}{$\begin{array}{l}\text { Optimal } \\
\text { frequency }\end{array}$} & \multicolumn{3}{|c|}{$\begin{array}{l}\text { Spatial } \\
\text { resolution }\end{array}$} & \multicolumn{3}{|c|}{$\begin{array}{l}\text { Contrast } \\
\text { sensitivity }\end{array}$} \\
\hline & $\bar{N}$ & Mean & SD & $\bar{N}$ & Mean & SD & $\bar{N}$ & Mean & SD \\
\hline \multicolumn{10}{|l|}{2 and 3} \\
\hline Untreated eye & 41 & 5.10 & 0.15 & 36 & 12.56 & 0.13 & 31 & 17.55 & 0.26 \\
\hline Treated eye & 44 & 3.36 & 0.18 & 35 & 7.14 & 0.15 & 31 & 10.51 & 0.25 \\
\hline Difference (\%) & & 52.1 & & & 75.9 & & & 67.0 & \\
\hline Difference (log units) & & 0.18 & & & 0.25 & & & 0.22 & \\
\hline \multicolumn{10}{|l|}{4} \\
\hline Untreated eye & 47 & 4.99 & 0.20 & 41 & 12.42 & 0.18 & 41 & 20.97 & 0.26 \\
\hline Treated eye & 31 & 4.08 & 0.19 & 31 & 8.47 & 0.19 & 31 & 13.04 & 0.27 \\
\hline Difference (\%) & & 22.5 & & & 46.7 & & & 60.8 & \\
\hline Difference (log units) & & 0.09 & & & 0.17 & & & 0.21 & \\
\hline \multicolumn{10}{|l|}{5 and 6} \\
\hline Untreated eye & 81 & 4.56 & 0.17 & 79 & 10.51 & 0.17 & 78 & 19.98 & 0.30 \\
\hline Treated eye & 44 & 2.93 & 0.18 & 44 & 6.38 & 0.18 & 44 & 15.02 & 0.28 \\
\hline Difference (\%) & & 55.5 & & & 64.7 & & & 33.0 & \\
\hline Difference (log units) & & 0.19 & & & 0.22 & & & 0.12 & \\
\hline
\end{tabular}

The logarithmic mean value and its SD (in log units) are shown for each parameter for neurons tested through the treated and untreated eye; the interocular difference is expressed as a percentage (by which the untreated eye's value exceeds the treated eye's) and in log units. 
V4 complex (Zeki, 1971, 1977). Though this small sample is plainly not adequate to support general conclusions concerning the extrastriate effects of unilateral blur, it is noteworthy that the data from this penetration showed weaker effects of the same general pattern as our V1 recordings. Figure 8 shows the eye dominance of these neurons, revealing that we encountered a substantial proportion of monocular or nearly monocular neurons. The data of Zeki (1978) show that, in normally reared monkeys, neurons in this area of cortex are almost invariably binocularly driven suggesting that the atropine rearing substantially reduced binocular interaction. Interestingly, there was again a relationship between eye dominance and neuronal spatial properties. The mean contrast sensitivity of neurons dominated by the treated eye (3.8) was $59 \%$ lower than that of neurons dominated by the untreated eye (6.1). There was also a slight difference in spatial resolution: the mean spatial resolution of 20 neurons dominated by the treated eye was $5.13 \mathrm{c} / \mathrm{deg}$, while the mean resolution of 28 neurons dominated by the untreated eye was $5.83 \mathrm{c} / \mathrm{deg}$, a difference of $14 \%$.

\section{Discussion}

\section{Blur-induced changes in visual cortical receptive fields}

The most striking effects of early unilateral blur on the physiological properties of cortical neurons are the changes we observed in the spatial properties of their receptive fields. Unlike more severe forms of deprivation, early blur does not invariably produce substantial shifts in eye dominance away from the deprived eye; instead, the effects of deprivation are most clearly expressed by abnormalities in the properties of neurons that remain driven by the deprived eye.

Site of the effects. Our evidence suggests that the selective effect on the spatial properties of cortical neurons is primarily of cortical rather than subcortical origin. The results of our recordings in the LGN (Fig. 7) do not confirm the claim of Ikeda and Tremain (1978) that, in cats, early unilateral blur deleteriously affects the spatial resolving power of LGN neurons. Moreover, our analysis of the effect of blur-rearing on different cortical laminae suggests that the effect is most strongly expressed in cortical neurons outside layer 4 (Table 4). Because our layer 4 sample includes some neurons from layer $4 \mathrm{~B}$, which does not receive direct LGN input, our data do not exclude the possibility that first-order cortical neurons, like LGN neurons, show little or no effect of blur rearing. In this respect, perhaps, atropine-treated animals have some similarity to monocularly deprived animals whose deprivation is of late onset (Hubel et al., 1977; Blakemore et al., 1978; LeVay et al., 1980); in such animals, the effects of deprivation are also primarily expressed outside layer 4.

Basis of the effects. The exact nature of the changes in cortical receptive fields in these monkeys cannot readily be discerned from our data. A suitable general model that could describe the effects is that the spatial precision with which LGN signals converge on cortical neurons driven by the treated eye is reduced compared to that shown by inputs from the normal eye. Note that this convergence could (and indeed is likely to) take place over several synaptic stages within the cortex. Anatomically, then, the loss of precision could be scen either in the geniculocortical projection pattern or in the organization of intracortical projections. The effect of the imprecision would be to "blur" or otherwise disrupt the detailed spatial organization of cortical receptive fields; this would account for the reduced spa-

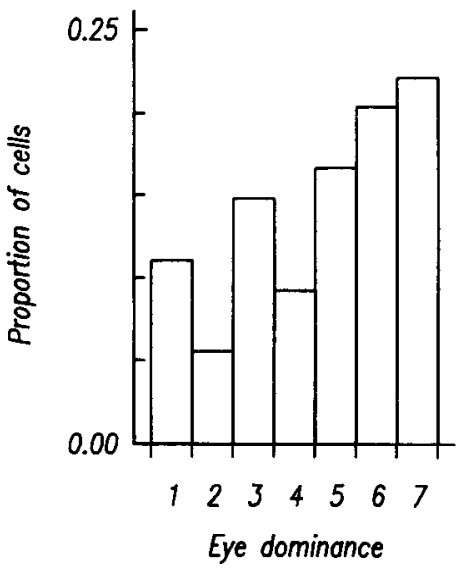

Figure 8. Eye dominance of 54 neurons recorded from the extrastriate cortex (probably area V4) of monkey TC. The eye dominance scale, as in earlier figures, is plotted as though the treated eye were contralateral to the recording site. In this case, the recordings were, in fact, from the hemisphere contralateral to the treated eye.

tial resolution and optimal spatial frequency that we observed. This imprecision would also be expected to reduce cortical contrast sensitivity. In a geniculocortical projection of normal precision, the antagonistic regions of LGN receptive fields are presumably organized so that they act synergistically to produce cortical receptive fields of high sensitivity; disruption of the spatial orderliness of the projection would cause these regions to act, at least in part, to antagonize one another, resulting in a loss of sensitivity. It is also possible, of course, that the effective gain of the geniculate input from the treated eye is reducedperhaps by a reduced number of synapses-accounting for some portion of the sensitivity loss.

Another possible explanation for our results could be that the normal balance of signals from the parvocellular and magnocellular portions of the $\mathrm{LGN}$ is disrupted in the atropine-treated animals. Recall that the anatomical effects of blur on both cortical cytochrome oxidase distribution and geniculate cell size suggest that the parvocellular system is disrupted much more than the magnocellular system (Hendrickson et al., 1987). It is parvocellular neurons that relay information about fine spatial detail to the cortex (Fig. 7; Derrington and Lennie, 1984; Kaplan and Shapley, 1982; Sherman et al., 1984). If the influence of parvocellular signals from the atropine-treated eye were reduced, and perhaps replaced in some competitive fashion by signals from magnocellular neurons, then one would expect the reduced spatial resolving power that we observed. It is worth noting in this context that the period of growth of magnocellular LGN cells extends well beyond that of parvocellular cells (Headon et al., 1981), suggesting that the magnocellular system's period of developmental plasticity might extend later than that of the parvocellular system. However, it must be noted that experiments on the consequences of reversed eyelid suture on cortical ocular dominance columns (LeVay et al., 1980) suggest the opposite, that parvocellular afferents have a more extended period of plasticity than magnocellular ones.

Binocular interaction. Another point that deserves attention conccrns the loss of binocularity that we observed in cortical cells in these monkeys. There is no obvious reason for binocular interaction to be reduced by unilateral blur, at least for neurons preferring relatively low spatial frequencies. As far as we could establish from cover testing and from the alignment of the visual 
axes during recording, none of the atropine-treated animals had a strabismus, so at least low spatial frequency components of images would be expected to fall in register on the 2 retinae. A possible explanation is that the change in the spatial properties of inputs from the 2 eyes reduces the binocular correlation necessary for the preservation of binocular connections (Hubel and Wiesel, 1965). The properties of the binocularly activated neurons that we studied in detail (Fig. 5) suggest that the nature of input signals from the 2 eyes did indeed differ substantially, and perhaps the converging signals from adjacent eye dominance columns were sufficiently different for binocularity-clearly a fragile property of the visual cortex - to break down.

\section{Relationships among behavior, anatomy and physiology}

In this and the previous 2 papers we have described a constellation of changes that follow early partial visual deprivation by image blur. Measured behaviorally, the visual capacities of our monkeys were impaired, especially in terms of contrast sensitivity at high spatial frequencies (Kiorpes et al., 1987). Anatomically, we found a pattern of geniculate and cortical effects that suggested a marked loss in the function of the portions of the visual pathway related to the parvocellular system of the LGN (Hendrickson et al., 1987). Physiologically, the most prominent effect of the rearing was a reduction in the spatial resolution and contrast sensitivity of striate cortical neurons driven by the treated eye. In all 3 kinds of experiment, the effect of early blur varied from animal to animal in a consistent fashion. For example, monkey TC had a rather modest behavioral sensitivity loss, relatively slight changes in LGN cell size that were confined to the parvocellular layers, and relatively subtle changes in the eye dominance and spatial properties of cortical neurons. Monkey $\mathrm{DH}$, on the other hand, showed a very profound loss of visual capacity in the treated eye, substantial differences in LGN cell size between treated- and untreated-eye layers, and a very substantial change both in cortical eye dominance and in the spatial properties of the neurons that remained driven by the treated eye. The other experimental animals ranged themselves in an orderly way between these 2 extreme cases. It is natural to seek a unified explanation of this correlated variability in the response of the visual system to the disruption of its early environment.

The most reasonable explanation sccms to be that the functional effects of early blur are directly related to the severity of the blur experienced. We do not have completely documented histories of the refractive state of our monkeys during their rearing, but we do have data on their refractive state at the onset of treatment and after the end of treatment (see Table 1 and Kiorpes et al., 1987). The animals did not differ consistently in terms of their refractive state at the beginning of treatment, but the final refractive error in the treated eye appears to be a reasonable predictor of the magnitude of the effects. For example, monkeys TC and LD had final refractive errors in their treated eyes near $3 \mathrm{D}$ and showed rather modest effects; monkeys DH and NW had errors between 5 and $6 \mathrm{D}$, and showed much more dramatic effects.

It is, of course, reasonable to suppose that the magnitude of the refractive error (and of the consequent blur) should determine the naturc and extent of functional changes in these animals, simply because of the differences in retinal image quality and consequent visual stimulation through the treated eye. It is worth noting in addition, however, that differences in the degree of blur experienced may also correspond to deprivation whose onset occurs at different ages. This is due to the fact that the visual acuity of monkeys develops for several months after birth (Teller et al., 1978). An animal experiencing modest image blur will receive effectively normal visual stimulation while its visual pathway is incapable of responding to the high spatial frequencies whose contrast is most attenuated Later, when the spatial vision of the animal improves, the deprivation becomes effective. On the other hand, an animal experiencing severe image blur will be deprived from the onset of the treatment. This effective difference in onset may also account in part for the differential effects of early blur on the parvocellular and magnocellular pathways. If, as suggested by the reverse-suture results of LeVay et al. (1980), the period of plasticity of the magnocellular system ends before that of the parvocellular system, then animals with modest degrees of blur may only be deprived during periods in which the parvocellular system is susceptible. Animals experiencing greater blur would also be affected earlier, during the period of magnocellular plasticity, which could account for the occurrence of magnocellular changes in some animals (Hendrickson et al., 1987).

The atropine-treated monkey appears to represent a good model of human anisometropic amblyopia (Sen, 1980; Bradley and Freeman, 1981; Bradley et al., 1985). Our anatomical and physiological results thus bear directly on the nature of the functional changes that underlie this condition. The functional changes in the less affected animals are most prominently expressed in the loss of spatial resolution and contrast sensitivity of cortical neurons, suggesting that this underlies the changes seen in more modest amblyopes. As we have noted, these changes may result primarily from degradation of the function of parvocellular portions of the visual pathway. More seriously affected animals show not only the changes in cortical propertics seen in the other animals, but also appear to have substantially less cortical territory devoted to processing signals from the amblyopic eye. In these cases, it may be the reduced number of available neurons, as well as the changes in their properties, that leads to the severity of the amblyopic deficit. Interestingly, 3 monkeys given artificial esotropic strabismus and studied using identical methods (Eggers et al., 1984) showed qualitatively similar but quantitatively larger effects: All these animals had strongly skewed eye dominance distributions and large interocular differences in spatial performance and contrast sensitivity. Thus our results suggest that changes in cortical eye dominance are not necessary for the production of mild amblyopia but are probably important when amblyopia is severe.

\section{References}

Baker, F. H., P. Grigg, and G. K. von Noorden (1974) Effects of visual deprivation and stabismus on the response of neurons in the visual cortex of the monkey, including studies on the striate and prestriate cortex of the normal animal. Brain Res. 66: 185-208.

Blakemore, C. (1976) The conditions required for the maintenance of binocularity in the kitten's visual corlex. J. Physiol. (Lond.) 261:423444.

Blakemore, C., and H. M. Eggers (1978) Animal models for human visual development. In Frontiers of Visual Science, S. J. Cool and E. L. Smith, eds., Springer-Verlag, New York.

Blakemore, C., L. J. Garey, and F. Vital-Durand (1978) The physiological effects of monocular deprivation and their reversal in the monkey's visual cortex. J. Physiol. (Lond.) 283: 223-262.

Boothe, R. G., L. Kiorpes, and A. E. Hendrickson (1982) Anisometropic amblyopia in Macaca nemestrina monkeys produced by atro- 
pinization of one eye during development. Invest. Ophthalmol. Vis. Sci. 22: 228-233.

Bradley, A. F., and R. D. Freeman (1981) Contrast sensitivity in anisometropic amblyopia. Invest. Ophthalmol. Vis. Sci. 21:467-476.

Bradley, A. F., R. D. Freeman, and R. Applegate (1985) Is amblyopia spatial frequency or retinal locus specific? Vision Res. 25: 47-54.

Crawford, M. L. J. (1978) The visual deprivation syndrome. Ophthalmology 85: 465-477.

De Valois, R. L., D. G. Albrecht, and L. G. Thorcll (1982) Spatial frequency selectivity of cells in macaque visual cortex. Vision Res. 22: 545-559.

Derrington, A. M., and P. Lennie (1984) Spatial and temporal contrast sensitivity of neurones in lateral geniculate nucleus of macaque. $\mathbf{J}$. Physiol. (Lond.) 357: 219-240.

Eggers, H. M., M. S. Gizzi, and J. A. Movshon (1984) Spatial properties of striate cortical neurons in esotropic macaques. Invest. Ophthalmol. Vis. Sci. Suppl. 25: 278.

Enroth-Cugell, C., and J. G. Robson (1966) The contrast sensitivity of retinal ganglion cells of the cat. J. Physiol. (Lond.) 187: 517-552.

Headon, M. P., J. J. Sloper, R. W. Hiorns, and T. P. S. Powell (1981) Cell sizes in the lateral geniculate nucleus of normal infant and adult rhesus monkeys. Brain Res. 229: 183-186.

Hendrickson, A. E., J. A. Movshon, H. M. Eggers, M. S. Gizzi, R. G. Boothe, and L. Kiorpes (1982) Anatomical and physiological effects of early unilateral blur. Invest. Ophthalmol. Vis. Sci. Suppl. 22: 237.

Hendrickson, A. E., J. A. Movshon, H. M. Eggers, M. S. Gizzi, R. G. Boothe, and L. Kiorpes (1987) Effects of early unilateral blur on the macaque's visual system: II. Anatomical observations. J. Neurosci. 7: 1327-1339.

Hubel, D. H., and T. N. Wiesel (1962) Receptive fields, binocular interaction and functional architecture in the cat's visual cortex. J. Physiol. (Lond.) 160: 106-154.

Hubel, D. H., and T. N. Wiesel (1965) Binocular interaction in striate cortex of kittens reared with artificial squint. J. Neurophysiol. 28: 1041-1059.

Hubel, D. H., and T. N. Wiesel (1968) Receptive fields and functional architecture of monkey striate cortex. J. Physiol. (Lond.) 195: 215243.

Hubel, D. H., and T. N. Wiesel (1977) Functional architecture of macaque monkey visual cortex. Proc. R. Soc. London [Biol.] 198: 159.

Hubel, D. H., T. N. Wiesel, and S. LeVay (1977) Plasticity of ocular dominance columns in monkey striate cortex. Phil. Trans. R. Soc. London [Biol.] 278: 377-409.

Ikeda, H., and K. E. Tremain (1978) Amblyopia resulting from penalisation: Neurophysiological studies of kittens reared with atropinisation of one or both eyes. Br. J. Ophthalmol. 62: 21-28.

Kaplan, E., and R. M. Shapley (1982) X and $Y$ cells in the lateral geniculate nucleus of macaque monkeys. J. Physiol. (Lond.) 330:125143.

Kiorpes, L., R. G. Boothe, A. E. Hendrickson, J. A. Movshon, H. M. Eggers, and M. S. Gizzi (1987) Effects of early unilateral blur on the macaque's visual system: I. Behavioral observations. J. Neurosci. 7: $1318-1326$.

LeVay, S., D. H. Hubel, and T. N. Wiesel (1975) The pattern of ocular dominance columns in macaque visual cortex revealed by a reduced silver stain. J. Comp. Neurol. 159: 559-576.

LeVay, S., T. N. Wiesel, and D. H. Hubel (1980) The development of ocular dominance columns in normal and visually deprived monkeys. J. Comp. Neurol. 191: 1-51.

Levick, W. R. (1972) Another tungsten microelectrode. Med. Biol. Engin. 10: 510-515.

Linsenmeier, R. A., L. J. Frishman, H. G. Jakiela, and C. Enroth-Cugell
(1982) Receptive field properties of $X$ and $Y$ cells in the cat retina derived from contrast sensitivity measurements. Vision Res. 22: 11731183.

Maffei, L., and A. Fiorentini (1973) The visual cortex as a spatial frequency analyzer. Vision Res. 13: 1255-1267.

Maffei, I., and A. Fiorentini (1977) Spatial frequency rows in the striate visual cortex. Vision Res. 17: 257-264.

Merrill, E. G., and A. Ainsworth (1972) Glass-coated platinum-plated microelectrodes. Med. Biol. Engin. 10: 662-671.

Movshon, J. A., I. D. Thompson, and D. J. Tolhurst (1978a) Spatial summation in the receptive fields of simple cells in the cat's striate corlex. J. Physiol. (Lond.) 283: 57-77.

Movshon, J. A., I. D. Thompson, and D. J. Tolhurst (1978b) Receptive field organization of complex cells in the cat's striate cortex. J. Physiol. (Lond.) 283: 79-99.

Movshon, J. A., I. D. Thompson, and D. J. Tolhurst (1978c) Spatial and temporal contrast sensitivity of neurons in areas 17 and 18 of the cat's visual cortex. J. Physiol. (Lond.) 283: 101-120.

Schiller, P. H., B. L. Finlay, and S. L. Volman (1976) Quantitative studies of single cell properties in monkey striate cortex. II. Orientation specificity and ocular dominance. J. Neurophysiol. 39: 13201333.

Sen, D. K. (1980) Anisometropic amblyopia. J. Pediatr. Ophthalmol. Strab. 17: 180-184.

Sherman, S. M., R. A. Schumer, and J. A. Movshon (1984) Functional cell classes in the macaque's LGN. Soc. Neurosci. Abstr. 10: 799.

Stryker, M. P., and H. Sherk (1975) Modification of cortical orientation selectivity in the cat by restricted visual experience: $A$ reexamination. Science 190: 904-906.

Teller, D. Y., D. M. Regal, T. O. Videen, and E. Pulos (1978) Development of visual acuity in infant monkeys (Macaca nemestrina) during the early postnatal weeks. Vision Res. 18: 561-566.

Tolhurst, D. J., and I. D. Thompson (1982) Organization of neurones preferring similar spatial frequencies in cat striate cortex. Exp. Brain Res. 48: 217-227.

Tolhurst, D. J., J. A. Movshon, and A. F. Dean (1983) The statistical reliability of visual signals in single neurons in cat and monkey striate cortex. Vision Res. 23: 775-785.

Tootell, R. B. H., M. S. Silverman, and R. L. DeValois (1981) Spatial frequency columns in primary visual cortex. Science 214: 813-815.

von Noorden, G. K., and M. L. J. Crawford (1977) Form deprivation without light deprivation produces the visual deprivation syndrome in Macaca mulatta. Brain Res. 129: 37-44.

von Noorden, G. K., and M. L. J. Crawford (1979) Morphological and physiological changes in the monkey visual system after shortterm lid suture. Invest. Ophthalmol. Vis. Sci. 17: 762-768.

Wiesel, T. N., and D. H. Hubel (1963) Single-cell responses in striate cortex of kittens deprived of vision in one eye. J. Neurophysiol. 26: 1003-1017.

Wiesel, T. N., and D. H. Hubel (1965) Comparison of the effects of unilateral and bilateral cyc closurc on cortical unit responses in kittens. J. Neurophysiol. 28: 1029-1040.

Wiesel, T. N., and D. H. Hubel (1966) Spatial and chromatic interactions in the lateral geniculate body of the rhesus monkey. J. Neurophysiol. 29: 1115-1158.

Zeki, S. M. (1971) Cortical projections from two prestriate areas in the monkey. Brain Res. 34: 19-35.

Zeki, S. M. (1977) Colour coding in the superior temporal sulcus of rhesus monkey visual cortex. Proc. R. Soc. London [Biol.] 197: 195223.

Zeki, S. M. (1978) Uniformity and diversity of structure and function in rhesus monkey prestriate visual cortex. J. Physiol. (Lond.) 277: 273-290. 